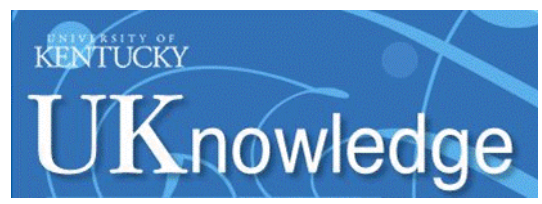

University of Kentucky

UKnowledge

$11-1-2012$

\title{
Multifactorial Patterns of Gene Expression in Colonic Epithelial Cells Predict Disease Phenotypes in Experimental Colitis
}

\author{
Aubrey Leigh Frantz \\ University of Kentucky, alfran2@uky.edu \\ Maria E. C. Bruno \\ University of Kentucky, maria.bruno@uky.edu \\ Eric William Rogier \\ University of Kentucky, ewrogi2@uky.edu \\ Halide Tuna \\ University of Kentucky, htuna2@uky.edu \\ Donald A. Cohen \\ University of Kentucky, don.cohen@uky.edu \\ Follow this and additional works at: https://uknowledge.uky.edu/microbio_facpub \\ Part of the Medical Immunology Commons, Medical Microbiology Commons, and the Molecular \\ See next page for additional authors \\ Genetics Commons
}

Right click to open a feedback form in a new tab to let us know how this document benefits you.

\section{Repository Citation}

Frantz, Aubrey Leigh; Bruno, Maria E. C.; Rogier, Eric William; Tuna, Halide; Cohen, Donald A.; Bondada, Subbarao; Chelvarajan, Ralph Lakshman; Brandon, J. Anthony; Jennings, C. Darrell; and Kaetzel, Charlotte S., "Multifactorial Patterns of Gene Expression in Colonic Epithelial Cells Predict Disease Phenotypes in Experimental Colitis" (2012). Microbiology, Immunology, and Molecular Genetics Faculty Publications. 128.

https://uknowledge.uky.edu/microbio_facpub/128

This Article is brought to you for free and open access by the Microbiology, Immunology, and Molecular Genetics at UKnowledge. It has been accepted for inclusion in Microbiology, Immunology, and Molecular Genetics Faculty Publications by an authorized administrator of UKnowledge. For more information, please contact UKnowledge@lsv.uky.edu. 


\title{
Multifactorial Patterns of Gene Expression in Colonic Epithelial Cells Predict Disease Phenotypes in Experimental Colitis
}

\author{
Digital Object Identifier (DOI) \\ https://doi.org/10.1002/ibd.22923 \\ Notes/Citation Information \\ Published in Inflammatory Bowel Diseases, v. 18, issue 11, p. 2138-2148. \\ Copyright @ 2012 Crohn's \& Colitis Foundation of America, Inc.
}

This is a pre-copyedited, author-produced version of an article accepted for publication in Inflammatory Bowel Diseases following peer review. The version of record, Frantz, A. L., Bruno, M. E. C., Rogier, E. W., Tuna, H., Cohen, D. A., Bondada, S., Chelvarajan, L. R., Brandon, A. J., Jennings, D. C., Kaetzel, C. S. (2011). Multifactorial Patterns of Gene Expression in Colonic Epithelial Cells Predict Disease Phenotypes in Experimental Colitis. Inflammatory Bowel Diseases, 18(11), 2138-2148, is available online at:

https://doi.org/10.1002/ibd.22923.

The copyright holder has granted the permission for posting the article here.

\section{Authors}

Aubrey Leigh Frantz, Maria E. C. Bruno, Eric William Rogier, Halide Tuna, Donald A. Cohen, Subbarao

Bondada, Ralph Lakshman Chelvarajan, J. Anthony Brandon, C. Darrell Jennings, and Charlotte S. Kaetzel 


\title{
Multifactorial Patterns of Gene Expression in Colonic Epithelial Cells Predict Disease Phenotypes in Experimental Colitis
}

\author{
Aubrey L. Frantz, B.S. ${ }^{*}$, Maria E.C. Bruno, Ph.D. ${ }^{*}$ Eric W. Rogier, B.S. ${ }^{\star}$, Halide Tuna, B.S. \\ Donald A. Cohen, Ph.D.", Subbarao Bondada, Ph.D. ${ }^{*}$ R. Lakshman Chelvarajan, Ph.D.. , J. \\ Anthony Brandon, Ph.D.", C. Darrell Jennings, M.D. ${ }^{\ddagger}$, and Charlotte S. Kaetzel, Ph.D. \\ "Department of Microbiology, Immunology and Molecular Genetics, University of Kentucky, \\ Lexington, Kentucky \\ ‡Department of Pathology and Laboratory Medicine, University of Kentucky, Lexington, Kentucky
}

\section{Abstract}

\begin{abstract}
Background-The pathogenesis of inflammatory bowel disease (IBD) is complex and the need to identify molecular biomarkers is critical. Epithelial cells play a central role in maintaining intestinal homeostasis. We previously identified 5 "signature" biomarkers in colonic epithelial cells (CEC) that are predictive of disease phenotype in Crohn's disease. Here we investigate the ability of CEC biomarkers to define the mechanism and severity of intestinal inflammation.
\end{abstract}

Methods-We analyzed expression of RelA, A20, pIgR, TNF and MIP-2 in CEC of mice with DSS acute colitis or T cell-mediated chronic colitis. Factor analysis was used to combine the 5 biomarkers into 2 multifactorial principal components (PCs). PC scores for individual mice were correlated with disease severity.

Results-For both colitis models, PC1 was strongly weighted toward RelA, A20 and pIgR, and PC2 was strongly weighted toward TNF and MIP-2, while the contributions of other biomarkers varied depending on the etiology of inflammation. Disease severity was correlated with elevated PC2 scores in DSS colitis and reduced PC1 scores in T cell transfer colitis. Down-regulation of pIgR was a common feature observed in both colitis models and was associated with altered cellular localization of pIgR and failure to transport IgA.

Conclusions-A multifactorial analysis of epithelial gene expression may be more informative than examining single gene responses in IBD. These results provide insight into the homeostatic and pro-inflammatory functions of CEC in IBD pathogenesis and suggest that biomarker analysis could be useful for evaluating therapeutic options for IBD patients.

\section{Keywords}

colonic epithelial cell; polymeric immunoglobulin receptor; experimental colitis; inflammatory bowel disease; gene expression; biomarkers

\section{INTRODUCTION}

Inflammatory bowel diseases (IBD), including Crohn's disease (CD) and ulcerative colitis (UC), are thought to result from inappropriate inflammatory responses to normal

Correspondence: Charlotte S. Kaetzel, Ph.D., Department of Microbiology, Immunology \& Molecular Genetics, University of Kentucky, 203 Combs Cancer Research Building, 800 Rose Street, Lexington, KY 40536-0096, Tel.: +1 859-257-6573, Fax: +1 859-257-8940, cskaet@uky.edu.

The authors state that they have no conflicts of interest relevant to this manuscript. 
components of the intestinal microbiota in genetically susceptible individuals ${ }^{1-3}$. Recent evidence has implicated both ineffective innate immune responses and overactive adaptive immune responses in the pathogenesis of IBD ${ }^{1,2,4-10}$. Colonic epithelial cells (CEC) bridge innate and adaptive immune responses through cross-talk with luminal bacteria and with lamina propria immune cells ${ }^{1,2,6}$. There is a critical need to identify cellular and molecular biomarkers that can predict disease behavior and guide personalized therapy, and a number of candidates have been proposed ${ }^{11-15}$. Considering the complex etiology and the heterogeneous clinical presentation of IBD, we propose that a multifactorial approach offers significant advantages over the use of single biomarkers for diagnosis and treatment of IBD.

Our group recently identified signature biomarkers in the colonic mucosa of $\mathrm{CD}$ patients that could be used in a multifactorial analysis to classify patients into molecular phenotypic subsets that were predictive of clinical characteristics and responses to therapy ${ }^{16}$. These biomarkers comprised 5 genes: the RelA subunit of NF- $\mathrm{kB}$; A20, a ubiquitin-modifying enzyme that negatively regulates the NF- $\kappa \mathrm{B}$ activation pathway; the polymeric immunoglobulin receptor (pIgR), which mediates epithelial transcytosis of $\operatorname{IgA}$ antibodies; the pro-inflammatory cytokine tumor necrosis factor (TNF), and the pro-inflammatory chemokine interleukin (IL)-8. The aim of the present study was to define patterns of biomarker gene expression that reflect the underlying mechanism and severity of intestinal inflammation. To this end we utilized two mouse models of colitis with very different etiologies. Oral administration of dextran sulfate sodium (DSS) induces acute colitis that is mediated primarily by effectors of innate immunity and causes damage to the epithelial barrier ${ }^{17}$. In contrast, adoptive transfer of naïve $\mathrm{T}$ cells into immunodeficient mice causes chronic colitis initiated by effector $\mathrm{T}$ cells and characterized by epithelial hyperplasia, goblet cell depletion and transmural inflammation ${ }^{18-21}$. We found different patterns of biomarker expression in these two models of experimental colitis that were predictive of disease severity. Importantly, down-regulation of expression and altered cellular localization of pIgR was a common feature of both colitis models. Furthermore, these defects were associated with failure to transport IgA. These results provide insights into the functions of CEC in regulation of intestinal inflammation, and provide proof of principle for the use of principal component analysis in the molecular diagnosis of intestinal inflammation.

\section{MATERIALS AND METHODS}

\section{Animals}

Six-week old female wild-type C57BL/6 and 8-week old female $\mathrm{Rag}^{-/-}$C57BL/6 mice were purchased from the Jackson Laboratories (Bar Harbor, ME). Mice were housed in microisolator cages with sterile bedding, food and water in AAALAC-accredited facility. All procedures were conducted in accordance with guidelines set forth by the University of Kentucky Institutional Animal Care and Use Committee.

\section{DSS Model of Acute Colitis}

Acute colitis was induced by oral administration of dextran sulfate sodium (DSS), as described $^{22}$. DSS (molecular weight 36,000 -50,000; MP Biomedicals, Aurora, OH) was dissolved in water at indicated concentration and given ad libitum to mice for 8 days in place of normal drinking water. Water intake was measured daily to ensure consistency in DSS intake among mice. A disease activity index (DAI) was calculated daily for each mouse during DSS treatment, on a 0-4 scale that assessed weight loss, stool consistency, and fecal blood (visible and occult), as described ${ }^{23}$. ColoScreen-ES testing kits (Helena Laboratories, Beaumont, TX) were used to detect occult blood. 


\section{T cell Transfer Model of Chronic Colitis}

Chronic colitis was induced by adoptive transfer of naïve $\mathrm{T}$ cells from wild-type mice into $\operatorname{Rag}^{-/}{ }^{-}$recipients, which lack B and T lymphocytes, as described ${ }^{19}$. To purify T-effector (Teff) and T-regulatory (Treg) cell populations for adoptive transfer, single cell suspensions from spleens of 10 week-old wild-type C57BL/6 mice were prepared in phosphate-buffered saline with $4 \%$ fetal bovine serum. In two of the three independent experiments, $\mathrm{CD} 4{ }^{+} \mathrm{CD} 45 \mathrm{RB}^{\mathrm{hi}}$ and $\mathrm{CD} 4{ }^{+} \mathrm{CD} 45 \mathrm{RB}^{\text {lo }}$ cell populations were isolated by fluorescenceactivated cell sorting. Spleen cells were labeled with anti-CD4 antibodies (eBiosciences, San Diego CA) and anti-CD45RB (Biolegend, San Diego CA) and sorted into CD4 ${ }^{+}$CD45RB ${ }^{\text {hi }}$ (as a source of Teff) and $\mathrm{CD} 4{ }^{+} \mathrm{CD} 45 \mathrm{RB}^{\text {lo }}$ fractions (as a source of natural Treg), defined as the uppermost $30 \%$ of cells with the brightest CD45RB staining and the lowest $15 \%$ of cells with the dimmest CD45RB expression, respectively (Supporting Fig. 1A). The Teff and Treg fractions were subsequently demonstrated to differ dramatically in cell surface expression of CD25, a marker for natural Treg (Supporting Fig. 1B). In one of the three independent experiments, $\mathrm{CD} 4^{+}$splenic T cells were separated into $\mathrm{CD} 25^{-}$(Teff) andCD25 $5^{+}$ (Treg) populations by magnetic bead sorting using the Regulatory T cells kit (Miltenyi, Auburn CA). Nine-week-old $\mathrm{Rag}^{-/-}$C57BL/6 mice received a single intraperitoneal injection of $4 \times 10^{5}$ purified Teff, with or without $1 \times 10^{5}$ purified Treg. Following adoptive transfer, body weight was monitored every 3 days and mice were sacrificed at 10 weeks post-transfer. No significant differences were observed in clinical parameters, tissue histology or colonic EC gene expression that could be attributed to the different methods of purification of Teff and Treg populations (immunofluorescence vs. magnetic beads).

\section{Tissue Histology}

Colons were dissected from euthanized mice and the length of the colon from the anus to the cecal junction was measured. For T cell transfer colitis, colons were weighed and the weight/length ratio was calculated. Colons were cut lengthwise, and half of each colon was prepared in a "Swiss roll" 24 and fixed in 10\% buffered formalin (Fisher Scientific, Fair Lawn, NJ). Fixed tissues were embedded in paraffin, sectioned, stained with hematoxylin and eosin, and evaluated in a blinded fashion for evidence of inflammation and epithelial damage. For DSS-induced colitis, tissue damage was quantified on a scale from 0-4 as previously described ${ }^{29}$, using the following criteria: 0 , no change from normal tissue; grade 1 , mild inflammation present in the mucosa, comprised mainly of mononuclear cells, with little epithelial damage; grade 2, multifocal inflammation greater than a grade 1 score, including mononuclear cells and some neutrophils, detachment of crypt glands from the muscularis mucosae, mucin depletion from goblet cells, and occasional detachment of the epithelium from the mucosa; grade 3 , multifocal inflammation greater than a grade 2 score, including mononuclear cells and neutrophils infiltrating the submucosa, crypt abscesses present with increased mucin depletion, and significant epithelial disruption, including some ulceration; grade 4, crypts no longer present, severe mucosal inflammation mainly composed of neutrophils, and epithelium no longer present or completely detached. For $\mathrm{T}$ cell transfer colitis, tissue damage was quantified by combining the scores for each of the following parameters for a maximum score of 17: degree of inflammation in the lamina propria (score 0-3); goblet cell loss (score 0-3); abnormal crypts (score 0-3); presence of crypt abscesses (score 0-1); mucosal erosion and ulceration (score 0-1); transmural involvement (score 0-3); and number of neutrophils counted at 40x magnification (score 0 3 ). For both models of colitis, an average of 4 fields of view per colon were evaluated for each mouse to obtain a composite score.

\section{Colonic Epithelial Cell Isolation}

CEC were isolated as previously described ${ }^{25}$. Colons were opened longitudinally, cut into 1 $\mathrm{mm}$ pieces, and the mucus layer was removed by incubation for $20 \mathrm{~min}$ with agitation at 
$37^{\circ} \mathrm{C}$ in a solution of $1 \mathrm{mM}$ dithiothreitol (Sigma, St. Louis MO) in DMEM:Ham's F-12 (1:1) tissue culture medium (Lonza, Walkersville MD), supplemented with 5\% fetal bovine serum and antibiotics (100 U/ml penicillin, $100 \mu \mathrm{g} / \mathrm{ml}$ streptomycin, and $250 \mathrm{ng} / \mathrm{ml}$ fungizone) (Invitrogen Life Technologies, Carlsbad CA). The supernatants were discarded, and CEC were stripped from the colon pieces by incubation for $1 \mathrm{~h}$ at $37^{\circ} \mathrm{C}$ in a solution of $0.5 \mathrm{M}$ EDTA in supplemented tissue culture media. The suspension was vortexed vigorously, and the remaining colon fragments were allowed to settle at the bottom of the flask. The upper layers were centrifuged at $2000 \mathrm{rpm}$ for 10 minutes at $4^{\circ} \mathrm{C}$ to collect ECs. Further purification of the CEC fraction was accomplished by resuspension of the cell pellets in a $10 \mathrm{ml}$ solution of 30\% w/v Percoll (Sigma) and centrifugation at $1300 \mathrm{rpm}$ for 20 min at room temperature. The top layer containing floating CEC was removed and transferred into a $15 \mathrm{ml}$ conical tube. The volume was brought to $10 \mathrm{ml}$ with supplemented tissue culture medium, and the CEC solution was pelleted by centrifugation at $2000 \mathrm{rpm}$ for $10 \mathrm{~min}$ at $4{ }^{\circ} \mathrm{C}$. CEC viability, assessed by trypan blue exclusion, was typically $>90 \%$. Flow cytometry analysis of representative CEC preparations indicated that contamination with $\mathrm{CD}^{+} 5^{+}$hematopoietic cells was approximately $0.4 \%$ for control mice and $1.3 \%$ for DSStreated mice (Supporting Fig. 2).

\section{Analysis of mRNA Levels by Real-time PCR}

mRNA levels for individual genes were analyzed by quantitative reverse transcriptasepolymerase chain reaction (qRT-PCR) as previously described ${ }^{26}$. Total RNA was purified from isolated CEC using the Qiagen RNeasy Protect mini kit (Qiagen, Germantown MD). RNA was reverse-transcribed to generate cDNA templates using the TaqMan Gold RT-PCR kit (Applied Biosystems, Foster City, CA). Specific mRNA levels were quantified by quantitative real-time polymerase chain reaction, using the ABI Prism 7700 Sequence Detection System (Applied Biosystems) as previously described ${ }^{26}$. The level of $\beta 2$ microglobulin mRNA, which we found did not vary with experimental treatments, was used to normalize mRNA for tested genes according to the following formula: $\left(2^{-\left(\mathrm{C}_{\mathrm{T}} \text { test }-\mathrm{C}_{\mathrm{T}} \beta 2 \text {-microglobulin }\right)}\right) \times 100 \%$.

\section{Immunofluorescence microscopy}

Sections of formalin-fixed, paraffin-embedded colon tissues were dewaxed and rehydrated using standard protocols. Antigen retrieval was performed by incubating slides for $20 \mathrm{~min}$ at $95^{\circ} \mathrm{C}$ in $25 \mathrm{ml}$ of $10 \mathrm{mM}$ sodium citrate buffer, $\mathrm{pH}$. Endogenous peroxidase activity was quenched by incubation for $10 \mathrm{~min}$ at room temperature in $25 \mathrm{ml}$ of $3 \%(\mathrm{v} / \mathrm{v}) \mathrm{H}_{2} \mathrm{O}_{2}$. Cellassociated $\mathrm{pIgR}$ and free secretory component (the cleaved extracellular domain of $\mathrm{pIgR}$ ) were detected by overnight incubation of tissue sections at $4{ }^{\circ} \mathrm{C}$ with a polyclonal goat antibody to mouse secretory component $(2.5 \mu \mathrm{g} / \mathrm{ml})$ (R\&D Systems, Minneapolis, MN). Sections were washed with PBS and incubated for $30 \mathrm{~min}$ at room temperature with a horseradish peroxidase-conjugated rabbit antibody to goat $\operatorname{IgG}(1 \mu \mathrm{g} / \mathrm{ml})$ (Invitrogen, Camarillo CA). Bound peroxidase was revealed with TSA Plus-TMR Reagent (PerkinElmer, Waltham MA). IgA was detected in the same tissue sections by subsequent incubation for 1 hour at room temperature with FITC-conjugated antibody to mouse $\operatorname{IgA}$ $(1 \mu \mathrm{g} / \mathrm{ml})$ (eBiosciences, San Diego CA). All antibodies were diluted in Blocking Reagent (Perkin-Elmer). Sections were mounted with VectaShield (Vector Laboratories, Burlingame CA) containing DAPI to visualize nuclei. Stained tissue sections were imaged on a Zeiss Axiophot confocal microscope with Axiovision image software.

\section{Statistical Analysis}

Statistical differences in disease parameters and mRNA levels among treatment groups were determined by analysis of variance and Fisher's protected least significant difference test. Correlation $Z$ test was used to test for correlations among mRNA levels for different 
biomarkers. Factor analysis was used to reduce the 5 mRNA biomarkers into two principal components (PCs), as previously described ${ }^{27}$. To assign scores for PC1 and PC2, the mRNA level for each of the 5 biomarkers for each mouse was first normalized to the mean for that biomarker for all mice within the DSS protocol or the $\mathrm{T}$ cell transfer protocol. Individual scores for $\mathrm{PC} 1$ and $\mathrm{PC} 2$ were calculated as the sum of the normalized value for each biomarker multiplied by the weight for that biomarker. Linear regression analysis was used to compare PC1 or PC2 values with \% initial weight, colon length or the ratio of colon weight/length, and histological score. All statistical analyses were performed using StatView Software (SAS Institute, Cary, NC).

\section{RESULTS}

\section{Assessment of disease severity in DSS and T cell-mediated colitis}

Acute colitis induced by oral administration of DSS resulted in significant weight loss, disease activity (diarrhea and blood loss) and pathological findings (colon shortening), with more severe symptoms in mice administered 3\% DSS than 2\% DSS (Fig. 1A,B). Tissue damage, including edema, goblet cell loss, ulcerations, epithelial cell destruction, and infiltration of inflammatory cells, was observed in all DSS-treated mice and was more severe in mice treated with 3\% DSS (Fig. 1C). Chronic colitis induced by adoptive transfer of $\mathrm{CD} 4{ }^{+} \mathrm{CD} 45 \mathrm{RB}^{\text {hi }} \mathrm{CD} 25^{-}$Teff cells into $\mathrm{Rag} 1^{-/-}$recipients resulted in a different clinical picture involving weight loss and an increased ratio of colon weight/length (Fig. 1D,E), but no symptoms of acute colitis such as diarrhea or blood loss (data not shown). Coadministration of $\mathrm{CD} 4{ }^{+} \mathrm{CD} 45 \mathrm{RB}^{\mathrm{lo}} \mathrm{CD} 25^{+}$Treg with Teff corrected the clinical symptoms of $\mathrm{T}$ cell-mediated colitis. Interestingly, colon tissues from control $\mathrm{Rag} \mathrm{I}^{-/-}$mice exhibited a significantly shorter epithelial crypt length than did wild-type mice (compare Fig. 1B and 1E) suggesting that the absence of $B$ and $T$ lymphocytes impaired normal development of the colonic epithelium. Adoptive transfer of Teff, with or without Treg, resulted in extensive crypt lengthening (Fig. 1F). Histological evidence of Teff-mediated colitis included infiltration of lymphocytes and mononuclear cells into both the mucosa and submucosa, but fewer neutrophils. Some mucosal edema and epithelial damage was observed, but this was less severe than in acute DSS-mediated colitis mice (compare Fig. 1C and 1F). Coadministration of Treg with Teff resulted in a moderate reduction in the inflammatory infiltrate and lessened epithelial damage and mucosal edema.

\section{Differential expression of "signature" biomarkers in colonic epithelial cells in acute DSS- mediated and chronic T cell-mediated colitis}

We used these different models of experimental colitis to examine the relationship between the etiology of intestinal inflammation and gene expression in colonic ECs. RNA was extracted from isolated ECs, and levels of mRNA were analyzed for 5 "signature" biomarkers that we have used to classify IBD patients into molecular phenotypic subsets ${ }^{16}$, i.e., RelA, A20, pIgR, TNF and MIP-2 (a functional homolog of human IL-8) (Figure 2). While the overall patterns of biomarker expression varied considerably between DSS and T cell-mediated colitis, the one common feature was down-regulation of PIgR mRNA. Interestingly, co-administration of Treg with Teff prevented down-regulation of pIgR. These data are consistent with the notion that mucosal inflammation, independent of its cause, is sufficient to impair normal expression of pIgR. By contrast, down-regulation of the RelA subunit of NF- $\mathrm{KB}$ was a more consistent feature of T cell-mediated colitis than DSS colitis. Down-regulation of RelA in mice adoptively transferred with Teff was correlated with reduced expression of A20, a RelA target gene that is induced by the classical NF- $\mathrm{KB}$ pathway and acts as a negative feedback regulator of NF- $\kappa$ B activation ${ }^{28}$. Coadministration of Treg with Teff did not restore RelA mRNA to control levels, but was sufficient to prevent down-regulation of A20. Finally, acute DSS colitis was characterized 
by strong up-regulation of the pro-inflammatory genes TNF and MIP-2 in CEC, which was not seen in chronic $\mathrm{T}$ cell-mediated colitis.

\section{Multifactorial patterns of biomarker expression predict disease phenotype}

It is clear that synergistic interactions among multiple gene products are involved in inflammatory responses, thus we used a multifactorial approach to identify patterns of gene expression that are associated with different etiologies of colitis. Factor analysis by the principal component (PC) method is a statistical approach that is used to reduce the number of variables in a complex data set and to classify relationships between those variables. We previously used PC analysis, based on the 5 "signature" biomarkers described in Figure 2, to classify CD patients into molecular phenotypic subsets that were predictive of clinical disease ${ }^{16}$. Here we demonstrate different patterns of gene expression associated with DSS and T cell-mediated experimental colitis in mice (Fig. 3). Chi-square analysis indicated that variability in the gene expression data sets for both DSS colitis and T cell transfer colitis could be reduced to two PCs ( 10.0001$)$ (Fig. 3A). Eigen values indicated that the proportion of variance among mice in expression of these 5 variables that could be described by PC1 and PC2 together was $72.5 \%$ for DSS colitis and $75.1 \%$ for T cell transfer colitis.

The coefficients for each variable describe its relative contribution to PC1 and PC2. For both DSS colitis and T cell transfer colitis, PC1 was strongly weighted toward RelA, A20 and pIgR, with a negative weight for MIP-2. Interestingly, TNF had a minimal contribution to PC1 for DSS colitis, but contributed strongly to PC1 for T cell transfer colitis. PC2 was strongly weighted toward TNF and MIP-2 for both DSS colitis and T cell colitis. The relative contributions of RelA and A20 to PC2 differed for the two models, and pIgR did not contribute significantly to $\mathrm{PC} 2$ for either model. We conclude that the different patterns of epithelial gene expression reflect the different etiologies of DSS and T cell-mediated colitis and may be useful for predicting disease phenotype. To this end, each mouse was assigned a score for PC1 and PC2 based on the sum of the weighted expression levels for all 5 biomarkers (see Materials and Methods for details) (Fig. 3B). For the DSS model, PC1 scores did not vary significantly among treatment groups, whereas the score for PC2 increased significantly with increasing DSS dose. Interestingly, the opposite pattern held for $\mathrm{T}$ cell transfer colitis. Adoptive transfer with Teff resulted in a significantly lower PC1 score, which was prevented by co-administration of Treg, whereas no significant differences in PC2 scores were observed.

To investigate whether these multifactorial PCs could predict disease severity, we performed linear regression analysis to examine the relationship between PC1 and PC2 scores and clinical measures of disease (Fig. 4). In the DSS colitis model, increased PC2 scores were significantly correlated with weight loss, decreased colon length (a measure of disease severity in DSS colitis), ${ }^{29}$ and tissue damage (quantified by histological score). A different pattern was observed for the T cell transfer colitis model, in which decreased PC1 scores were significantly correlated with weight loss and an increased ratio of colonic weight/ length (a measure of disease severity in T cell transfer colitis). ${ }^{18,19}$ However, tissue damage in this model was significantly correlated with increased PC2 scores, similar to the pattern seen in DSS-induced colitis. Taken together, these results suggest that a multifactorial approach combining the expression of multiple biomarkers in colonic EC can be used to discriminate among different mechanisms of inflammation and to predict disease severity.

\section{Colonic inflammation results in altered localization of plgR and reduced epithelial transcytosis of IgA}

We previously reported that expression of pIgR and epithelial transcytosis of IgA were dysregulated in the colonic mucosa of Crohn's disease patients ${ }^{16}$. Because down-regulation 
of pIgR mRNA in CEC was a common feature of both DSS and T cell-mediated colitis (Fig. 2A,B), we hypothesized that epithelial transcytosis of IgA would also be altered.

Visualization of pIgR and IgA in sections of colonic tissue revealed reduced expression and aberrant localization of pIgR in the colonic epithelium in both DSS-induced (Fig. 5A) and T cell-mediated colitis (Fig. 5B). In untreated wild-type mice (Fig. 5A, left panel), pIgR expression was abundant and predominantly localized to the lower two-thirds of the epithelial crypts. Significant co-localization of pIgR and IgA was observed, consistent with normal transcytosis of IgA. However, in the colons of DSS-treated mice, pIgR staining was clearly reduced, consistent with reduced pIgR mRNA levels (Fig. 2A), and was not concentrated in the lower section of the crypts. Importantly, we also observed less colocalization of IgA and pIgR in DSS-treated mice, although the presence of IgA-producing plasma cells in the lamina propria was increased. Similar to wild-type mice, pIgR was predominantly localized to the lower two-thirds of the epithelial crypts in control $\mathrm{Rag}^{-/-}$ mice (Fig. 5B). No IgA was detected in the colons of these mice, since they lack B cells and cannot produce IgA. Total pIgR staining was markedly reduced in the $R a g 1^{-/-}$mice adoptively transferred with Teff, consistent with down-regulation of pIgR mRNA (Fig. 2B), and concentration of pIgR in the lower section of the crypts was not seen. Expression of pIgR was substantially restored when Treg cells were co-transferred with Teff (Fig. 5B), consistent with the restoration of pIgR mRNA levels (Fig. 2B). However, concentration of pIgR localization in the lower section of the crypts was not fully restored.

\section{DISCUSSION}

Molecular classification of IBD patients based on multifactorial patterns of biomarker expression offers the potential to personalize diagnosis and clinical management of this chronic and debilitating disease. Experimental mouse models of IBD have proven to be valuable tools for investigating mechanisms of IBD pathogenesis and for identifying potential therapeutic targets ${ }^{17,30}$. Oral administration of DSS causes concentration- and time-dependent cytotoxicity of intestinal epithelial cells, thus disrupting intestinal barrier function ${ }^{31}$. Because acute colitis could be induced by DSS in mice with severe combined immunodeficiency, which lack B and $\mathrm{T}$ lymphocytes ${ }^{32}$, it has long been thought that intestinal inflammation in this model is driven mainly by innate immune responses. However, more recent studies comparing DSS-induced colitis in immunodeficient and wildtype mice suggested that the presence of lymphocytes may exacerbate inflammation, particularly at low doses of DSS ${ }^{33}$. In the T cell transfer model, chronic colitis develops as a result of enteric antigen-driven activation, polarization and homeostatic expansion of naïve $\mathrm{T}$ cells to produce colitogenic Th1 and/or Th17 effectors cells ${ }^{17,18}$. Co-administration of $\mathrm{T}$ regulatory cells with $\mathrm{T}$ effector cells prevents induction of colitis, verifying a significant protective role for T regulatory cells in IBD pathogenesis ${ }^{19,34}$.

Here we have focused on a limited set of 5 "signature" epithelial biomarkers that we previously validated for prediction of disease severity in CD patients ${ }^{16}$. Given the heterogeneous clinical presentation in IBD, it is likely that a classification scheme based on multiple biomarkers will be more informative than the use of individual biomarkers. It is clear that the expression of many genes may change during intestinal inflammation. However, by focusing on only 5 highly informative genes, we have provided proof of principle that a multifactorial approach can transform a limited amount of data into a potentially powerful diagnostic tool. We have now identified distinctive expression patterns of these 5 biomarkers expression in two models of experimental colitis with different etiologies (Fig. 2). Principal component analysis reduced the 5 biomarkers into 2 multifactorial PCs that were specific for each model (Fig. 3) and were predictive of disease severity (Fig. 4). We propose that PC1 is a composite biomarker reflecting homeostatic epithelial barrier function, characterized by NF- $\mathrm{kB}$-stimulated physiological inflammation. 
The individual biomarkers RelA, A20 and pIgR were dominant contributors to PC1 in both colitis models. We previously reported that high expression of PC1 was associated with mild disease activity and good responses to therapy in $\mathrm{CD}$ patients ${ }^{16}$. We found that high expression of $\mathrm{pIgR}$ was correlated with robust epithelial transcytosis of IgA. While excessive NF- $\mathrm{kB}$ signaling in immune cells has been implicated as a major contributor to intestinal inflammation and the development of IBD, NF- $\kappa$ B signaling in epithelial cells has been shown to promote intestinal homeostasis ${ }^{35-37}$. Our finding of a potential protective role for NF- $\kappa \mathrm{B}$ signaling is consistent with the report of Eckmann et al. ${ }^{38}$ in which ablation of the NF- $\mathrm{KB}$-activating kinase IKK $\beta$ in intestinal epithelial cells resulted in an exacerbation of DSS-induced colitis. However, these investigators found that loss of epithelial IKK $\beta$ had no impact on chronic colitis that occurs spontaneously in IL-10-deficient mice. Thus the protective functions of epithelial-specific NF- $\mathrm{KB}$ signaling likely depend on specific etiology of intestinal inflammation. We found that epithelial expression of the proinflammatory genes TNF and IL-8 (or mouse MIP-2, a functional homolog of human IL-8) contributed strongly to PC2. While a normal range of PC2 values is consistent with NF- $\mathrm{kB}-$ stimulated physiological inflammation, high PC2 values may indicate an excessive and damaging inflammatory response. Here we found that disease severity in acute DSS colitis was correlated with elevated PC2 values, with no significant alterations in $\mathrm{PC} 1$ values. These results are consistent with our previous findings in CD patients, where a subset of recently-diagnosed patients with elevated PC2 values and variable $\mathrm{PC} 1$ values tended to present with acute inflammation that responded well to immunosuppressive and anti-TNF therapy ${ }^{16}$. In a recent analysis of these biomarkers in colonic biopsies of patients with UC, we observed a similar correlation between elevated PC2 values and acute inflammation (Bruno et al., unpublished data). These findings are significant in that many features of DSS colitis, such as macroscopic appearance and histological injury, more closely resemble acute inflammation in $\mathrm{UC}$ than $\mathrm{CD}^{39}$. In contrast, we found that some measures of disease severity in chronic T cell-mediated colitis (weight loss, colon weight/length ratio) were correlated with low PC1 values, whereas tissue damage in the colon was associated with high PC2 values. This pattern is similar to that observed in subsets of CD and UC patients with low PC1 and variable PC2 values, characterized by chronic inflammation and poor responses to immunosuppressive and anti-TNF therapy (Ref. 16 and Bruno et al., unpublished data). The results of our current study suggest that acute colitis mediated by innate immune responses is associated with increased epithelial expression of pro-inflammatory genes, whereas chronic colitis driven by adaptive $\mathrm{T}$ cell responses is associated with diminished expression of genes associated with homeostatic epithelial barrier function. These findings provide insights into the role of epithelial cells in the regulation of colonic inflammation, and support the use of these epithelial biomarkers for monitoring disease course and guiding therapy in IBD patients. We propose that multifactorial analysis of CEC gene expression may be valuable for monitoring the transition from acute to chronic colitis in IBD patients. This approach may enhance our understanding of immunological mechanisms underlying inflammation at different stages, which may require different therapeutic approaches, and may also help to identify patients at risk for sequelae associated with chronic inflammation, such as colitis-associated cancer.

A novel finding that emerged from this study was that expression of pIgR in CEC was down-regulated in both acute DSS and chronic T cell colitis (Fig. 2). Furthermore, DSSinduced inflammation was associated with reduced epithelial transcytosis of IgA (Fig. 5A). These results were consistent with our findings in CD patients with either acute or chronic colitis, in which expression of pIgR and transcytosis of IgA in CEC was reduced compared to normal individuals or $\mathrm{CD}$ patients with mild disease ${ }^{16}$. The importance of $\mathrm{pIgR}$ in prevention of intestinal inflammation is supported by the report that pIgR-deficient mice were more susceptible to DSS-induced colitis than were wild-type mice ${ }^{23}$. pIgR transports polymeric IgA from the basal to the apical surface of intestinal epithelial cells, where 
proteolytic cleavage of the extracellular domain of pIgR (secretory component, SC) releases secretory IgA (SIgA) into the intestinal lumen ${ }^{40,41}$. Because one molecule of $\mathrm{pIgR}$ is synthesized for every molecule of $\operatorname{IgA}$ transported, the level of pIgR expression controls the rate of epithelial transcytosis of $\operatorname{IgA}$. SIgA antibodies play a critical role in shaping the composition of the gut microbiota and in maintenance of intestinal homeostasis ${ }^{42}$. SIgA binds to intestinal mucus via glycan-mediated interactions, thus forming an immunological barrier to penetration of the epithelial layer by microbes and environmental antigens, and can also neutralize antigens and microbial products intracellularly during pIgR-mediated epithelial transcytosis. In addition, pIgR can transport IgA-containing immune complexes across polarized IEC monolayers, thus disposing of antigens through a non-inflammatory process ${ }^{43}$. Thus, reduction of pIgR expression during colitis would be predicted to diminish not only the antimicrobial function of luminal SIgA, but also removal of IgA-bound antigens from the lamina propria. These defects would exacerbate local inflammation and increase the level of $\operatorname{IgA}$ immune complexes, a potential risk factor for development of $\operatorname{IgA}$ nephropathy, which has been linked with $\mathrm{IBD}^{44}$.

It should be noted that a protective role for $\mathrm{pIgR}$ in the $\mathrm{T}$ cell transfer model of colitis could not involve transcytosis of SIgA, since B cell-deficient recipient Rag $^{-/-}$mice do not produce IgA. However, it is well known that free SC, which is released when pIgR that is not associated with IgA is cleaved at the apical surface of epithelial cells, contributes to intestinal homeostasis by inhibiting bacterial adherence to the intestinal mucus layer and neutralizing of potential pro-inflammatory factors ${ }^{45,46}$. We found that expression of pIgR mRNA was reduced (Fig. 2B) and the cellular localization of pIgR protein was aberrant (Fig. 5B) in Rag $1^{-/-}$mice adoptively transferred with Teff. Importantly, co-administration of Treg prevented both of these defects. Taken together, our results suggest that inflammation in the colon, whether due to innate immune responses in the DSS model or adaptive immune responses in the $\mathrm{T}$ cell model, creates a local environment that is not conducive to optimal expression and cellular trafficking of $\mathrm{pIgR}$.

We found that epithelial expression of TNF was significantly increased in acute DSS colitis (Fig. 2A) and contributed strongly to pro-inflammatory PC2, but not to homeostatic PC1 values (Fig. 3A). In contrast, altered epithelial expression of TNF was not a feature of $\mathrm{T}$ cell-mediated chronic colitis (Fig. 2B) and contributed to both PC1 and PC2 values (Fig. $3 \mathrm{~A})$. Although TNF expression was not elevated in CEC of mice with T cell-mediated colitis, we cannot rule out the possibility that production of TNF by other cell types contributes to intestinal inflammation in this model. We previously reported that expression of TNF in mucosal biopsies (which contain stromal and bone marrow-derived cells in addition to epithelial cells) was actually reduced in a large subset of CD patients with longstanding, chronic inflammation ${ }^{16}$. We recently reported that stimulation with TNF enhances expression of pIgR through a RelA-dependent mechanism in a human CEC line ${ }^{47}$, suggesting that physiological production of TNF in the colonic epithelium may contribute to intestinal homeostasis by promoting pIgR-mediated transcytosis of SIgA and innate immune functions of SC. However, failure to regulate TNF production clearly contributes to the pathogenesis of IBD. Biological therapies designed to neutralize TNF have been extremely useful in managing severe colitis ${ }^{48}$, and a recent report suggests that anti-TNF therapy may promote the activation and expansion of $\mathrm{T}$ regulatory cells in CD patients ${ }^{49}$. However, neutralization of TNF can be associated with significant adverse effects, including exacerbation of disease, serious infection and malignancies. Furthermore, anti-TNF therapies are only effective in about half of patients, and there are as yet no clear clinical guidelines regarding which anti-TNF drug to use first or how to manage patients who experience recurrence of symptoms ${ }^{50}$. Our findings in $\mathrm{CD}$ patients and in experimental models of colitis suggest that monitoring TNF expression in the colonic mucosa may be 
useful for understanding disease mechanisms and identifying those patients most likely to benefit from anti-TNF therapy.

\section{Supplementary Material}

Refer to Web version on PubMed Central for supplementary material.

\section{Acknowledgments}

Supported by the National Institutes of Health grants R21AI069027 (to CSK) and R21AI076956 (to SB) and a Crohn's \& Colitis Foundation of America Senior Research Award (to CSK).

\section{References}

1. Khor B, Gardet A, Xavier RJ. Genetics and pathogenesis of inflammatory bowel disease. Nature. 2011; 474:307-17. [PubMed: 21677747]

2. Maloy KJ, Powrie F. Intestinal homeostasis and its breakdown in inflammatory bowel disease. Nature. 2011; 474:298-306. [PubMed: 21677746]

3. Kaser A, Zeissig S, Blumberg RS. Genes and environment: how will our concepts on the pathophysiology of IBD develop in the future? Dig Dis. 2008; 28:395-405. [PubMed: 20926863]

4. Barnes MJ, Powrie F. Regulatory T cells reinforce intestinal homeostasis. Immunity. 2009; 31:40111. [PubMed: 19766083]

5. McGuckin MA, Eri R, Simms LA, Florin TH, et al. Intestinal barrier dysfunction in inflammatory bowel diseases. Inflamm Bowel Dis. 2009; 15:100-13. [PubMed: 18623167]

6. Roda G, Sartini A, Zambon E, et al. Intestinal epithelial cells in inflammatory bowel diseases. World J Gastroenterol. 2010; 16:4264-71. [PubMed: 20818809]

7. Cario E. Innate immune signalling at intestinal mucosal surfaces: a fine line between host protection and destruction. Curr Opin Gastroenterol. 2008; 24:725-32. [PubMed: 19122523]

8. Gersemann M, Wehkamp J, Fellermann K, et al. Crohn's disease--defect in innate defence. World J Gastroenterol. 2008; 14:5499-503. [PubMed: 18810765]

9. Hisamatsu T, Ogata H, Hibi T, et al. Innate immunity in inflammatory bowel disease: state of the art. Curr Opin Gastroenterol. 2008; 24:448-54. [PubMed: 18622158]

10. Abraham C, Medzhitov R. Interactions between the host innate immune system and microbes in inflammatory bowel disease. Gastroenterology. 2011; 140:1729-37. [PubMed: 21530739]

11. Scaldaferri F, Correale C, Gasbarrini A, et al. Mucosal biomarkers in inflammatory bowel disease: key pathogenic players or disease predictors? World J Gastroenterol. 2010; 16:2616-25. [PubMed: 20518083]

12. Siddiqui KR, Laffont S, Powrie F. E-cadherin marks a subset of inflammatory dendritic cells that promote T cell-mediated colitis. Immunity. 2010; 32:557-67. [PubMed: 20399121]

13. Singh K, Chaturvedi R, Barry DP, et al. The apolipoprotein E-mimetic peptide COG112 inhibits NF- $\kappa \mathrm{B}$ signaling, proinflammatory cytokine expression, and disease activity in murine models of colitis. J Biol Chem. 2011; 286:3839-50. [PubMed: 21115487]

14. Alex P, Zachos NC, Nguyen T, et al. Distinct cytokine patterns identified from multiplex profiles of murine DSS and TNBS-induced colitis. Inflamm Bowel Dis. 2009; 15:341-52. [PubMed: 18942757]

15. McBee ME, Zeng Y, Parry N, et al. Multivariate modeling identifies neutrophil- and Th17-related factors as differential serum biomarkers of chronic murine colitis. PLoS One. 2010; 5:e13277. [PubMed: 20976045]

16. Arsenescu R, Bruno ME, Rogier EW, et al. Signature biomarkers in Crohn's disease: toward a molecular classification. Mucosal Immunol. 2008; 1:399-411. [PubMed: 19079204]

17. te Velde AA, de Kort F, Sterrenburg E, et al. Comparative analysis of colonic gene expression of three experimental colitis models mimicking inflammatory bowel disease. Inflamm Bowel Dis. 2007; 13:325-30. [PubMed: 17206675] 
18. Ostanin DV, Bao J, Koboziev I, et al. T cell transfer model of chronic colitis: concepts, considerations, and tricks of the trade. Am J Physiol Gastrointest Liver Physiol. 2009; 296:G13546. [PubMed: 19033538]

19. Powrie F, Leach MW, Mauze S, Caddle LB, Coffman RL. Phenotypically distinct subsets of CD4+ $\mathrm{T}$ cells induce or protect from chronic intestinal inflammation in C. B-17 scid mice. Int Immunol. 1993; 5:1461-71. [PubMed: 7903159]

20. Singh B, Read S, Asseman C, et al. Control of intestinal inflammation by regulatory T cells. Immunol Rev. 2001; 182:190-200. [PubMed: 11722634]

21. Trobonjaca Z, Leithauser F, Moller P, et al. MHC-II-independent CD4+ T cells induce colitis in immunodeficient RAG-/- hosts. J Immunol. 2001; 166:3804-12. [PubMed: 11238623]

22. Qualls JE, Tuna H, Kaplan AM, et al. Suppression of experimental colitis in mice by CD11c+ dendritic cells. Inflamm Bowel Dis. 2009; 15:236-47. [PubMed: 18839426]

23. Murthy AK, Dubose CN, Banas JA, et al. Contribution of polymeric immunoglobulin receptor to regulation of intestinal inflammation in dextran sulfate sodium-induced colitis. J Gastroenterol Hepatol. 2006; 21:1372-80. [PubMed: 16911679]

24. Park CM, Reid PE, Walker DC, et al. A simple, practical 'swiss roll' method of preparing tissues for paraffin or methacrylate embedding. J Microsc. 1987; 145:115-20. [PubMed: 2437310]

25. Weigmann B, Tubbe I, Seidel D, et al. Isolation and subsequent analysis of murine lamina propria mononuclear cells from colonic tissue. Nat Protoc. 2007; 2:2307-11. [PubMed: 17947970]

26. Bruno ME, Rogier EW, Frantz AL, et al. Regulation of the polymeric immunoglobulin receptor in intestinal epithelial cells by Enterobacteriaceae: implications for mucosal homeostasis. Immunol Invest. 2010; 39:356-82. [PubMed: 20450283]

27. Ringner M. What is principal component analysis? Nat Biotechnol. 2008; 26:303-4. [PubMed: 18327243]

28. Shembade N, Ma A, Harhaj EW. Inhibition of NF- $\kappa$ B signaling by A20 through disruption of ubiquitin enzyme complexes. Science. 2010; 327:1135-9. [PubMed: 20185725]

29. Qualls JE, Kaplan AM, van Rooijen N, et al. Suppression of experimental colitis by intestinal mononuclear phagocytes. J Leukoc Biol. 2006; 80:802-15. [PubMed: 16888083]

30. Saleh M, Elson CO. Experimental inflammatory bowel disease: insights into the host-microbiota dialog. Immunity. 2011; 34:293-302. [PubMed: 21435584]

31. Ni J, Chen SF, Hollander D. Effects of dextran sulphate sodium on intestinal epithelial cells and intestinal lymphocytes. Gut. 1996; 39:234-41. [PubMed: 8991862]

32. Dieleman LA, Ridwan BU, Tennyson GS, et al. Dextran sulfate sodium-induced colitis occurs in severe combined immunodeficient mice. Gastroenterology. 1994; 107:1643-52. [PubMed: 7958674]

33. Kim TW, Seo JN, Suh YH, et al. Involvement of lymphocytes in dextran sulfate sodium-induced experimental colitis. World J Gastroenterol. 2006; 12:302-5. [PubMed: 16482634]

34. Boden EK, Snapper SB. Regulatory T cells in inflammatory bowel disease. Curr Opin Gastroenterol. 2008; 24:733-41. [PubMed: 19125486]

35. Pasparakis M. IKK/NF- $\kappa$ B signaling in intestinal epithelial cells controls immune homeostasis in the gut. Mucosal Immunol. 2008; 1 (Suppl 1):S54-7. [PubMed: 19079232]

36. Pasparakis M. Regulation of tissue homeostasis by NF- $\kappa$ B signalling: implications for inflammatory diseases. Nat Rev Immunol. 2009; 9:778-88. [PubMed: 19855404]

37. Wullaert A, Bonnet MC, Pasparakis M. NF- $\kappa$ B in the regulation of epithelial homeostasis and inflammation. Cell Res. 2011; 21:146-58. [PubMed: 21151201]

38. Eckmann L, Nebelsiek T, Fingerle AA, et al. Opposing functions of IKK $\beta$ during acute and chronic intestinal inflammation. Proc Natl Acad Sci USA. 2008; 105:15058-63. [PubMed: 18815378]

39. Kawada M, Arihiro A, Mizoguchi E. Insights from advances in research of chemically induced experimental models of human inflammatory bowel disease. World J Gastroenterol. 2007; 13:5581-93. [PubMed: 17948932]

40. Kaetzel CS. The polymeric immunoglobulin receptor: bridging innate and adaptive immune responses at mucosal surfaces. Immunol Rev. 2005; 206:83-99. [PubMed: 16048543] 
41. Norderhaug IN, Johansen FE, Schjerven H, Brandtzaeg P. Regulation of the formation and external transport of secretory immunoglobulins. Crit Rev Immunol. 1999; 19:481-508. [PubMed: 10647747]

42. Macpherson AJ, McCoy KD, Johansen FE, et al. The immune geography of IgA induction and function. Mucosal Immunol. 2008; 1:11-22. [PubMed: 19079156]

43. Kaetzel CS, Robinson JK, Chintalacharuvu KR, et al. The polymeric immunoglobulin receptor (secretory component) mediates transport of immune complexes across epithelial cells: a local defense function for IgA. Proc Natl Acad Sci USA. 1991; 88:8796-800. [PubMed: 1924341]

44. Peeters AJ, van den Wall Bake AW, et al. Inflammatory bowel disease and ankylosing spondylitis associated with cutaneous vasculitis, glomerulonephritis, and circulating IgA immune complexes. Ann Rheum Dis. 1990; 49:638-40. [PubMed: 2204314]

45. Phalipon A, Corthesy B. Novel functions of the polymeric Ig receptor: well beyond transport of immunoglobulins. Trends Immunol. 2003; 24:55-8. [PubMed: 12547499]

46. Corthesy B. Roundtrip ticket for secretory IgA: role in mucosal homeostasis? J Immunol. 2007; 178:27-32. [PubMed: 17182536]

47. Bruno ME, Frantz AL, Rogier EW, et al. Regulation of the polymeric immunoglobulin receptor by the classical and alternative NF- $\mathrm{B}$ pathways in intestinal epithelial cells. Mucosal Immunol. 2011; 4:468-78. [PubMed: 21451502]

48. Swaminath A, Lebwohl B, Capiak KM, et al. Practice Patterns in the Use of Anti-Tumor Necrosis Factor Alpha Agents in the Management of Crohn's Disease: A US National Practice Survey Comparing Experts and Non-Experts. Dig Dis Sci. 2011; 56(4):1160-4. [PubMed: 21181440]

49. Ricciardelli I, Lindley KJ, Londei M, et al. Anti tumour necrosis-alpha therapy increases the number of FOXP3 regulatory T cells in children affected by Crohn's disease. Immunology. 2008; 125:178-83. [PubMed: 18422560]

50. Clark M, Colombel JF, Feagan BC, et al. American gastroenterological association consensus development conference on the use of biologics in the treatment of inflammatory bowel disease, June 21-23, 2006. Gastroenterology. 2007; 133:312-39. [PubMed: 17631151] 
A

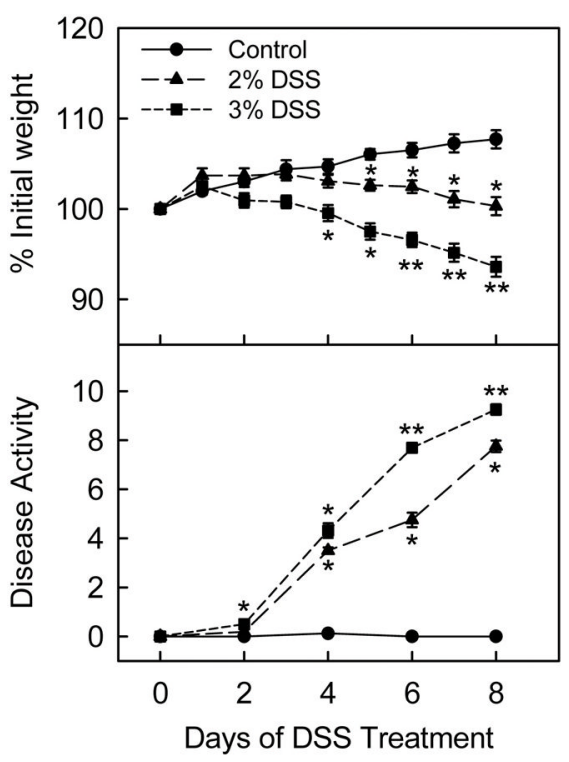

D

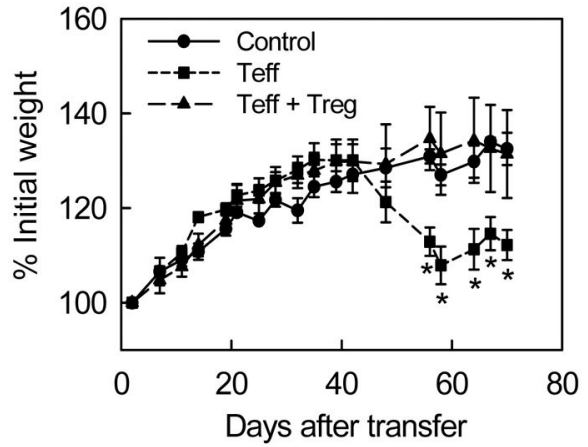

B

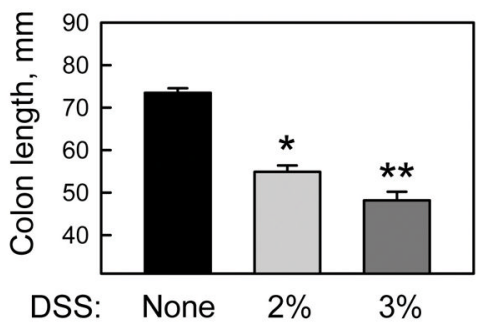

C

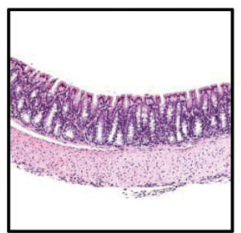

Control

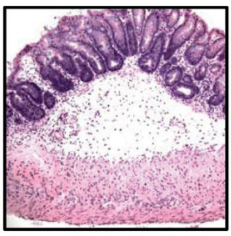

$2 \%$ DSS

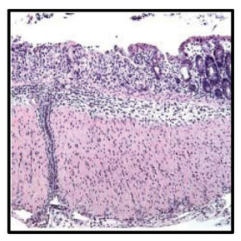

$3 \%$ DSS
E

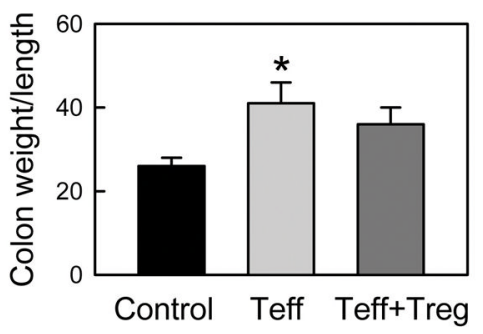

F

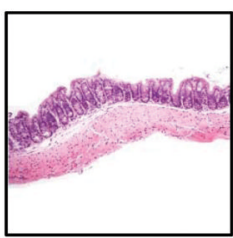

Control

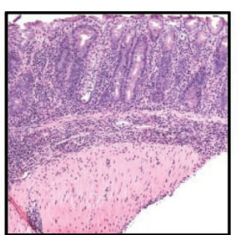

Teff

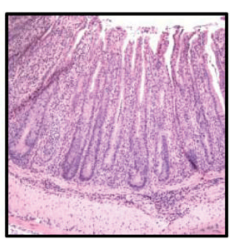

Teff + Treg

FIGURE 1.

Assessment of disease severity in DSS and T cell transfer colitis. (A-C) DSS colitis. Mice were left untreated or administered $2 \%$ or $3 \%$ DSS in the drinking water for 8 days. (A) Changes in body weight (expressed as a percentage of weight at the beginning of the experiment) and disease activity (see Materials and Methods for an explanation of the disease activity index). Data from 1 of 3 independent experiments with similar results are expressed as mean \pm SEM $(n=8)$. (B) Colon lengths were measured on day 8; data combined from 3 independent experiments are expressed as mean \pm SEM $(n=16)$. $(A, B)$ One asterisk indicates that the mean is significantly different from the mean for control mice, and two asterisks indicate that the mean is significantly different from the mean for both control mice and mice treated with $2 \%$ DSS $(\mathrm{p}<0.05)$. (C) Colon histology from 
representative mice at day 8 . Images of formalin-fixed colon tissues stained with hematoxylin and eosin were captured with a 20X objective.

(D-F) T cell transfer colitis. $\operatorname{Rag} 1^{-/}$mice were left untreated (control) or adoptively transferred with $4 \times 10^{5} \mathrm{CD} 4^{+} \mathrm{CD} 45 \mathrm{RB}^{\mathrm{hi}} \mathrm{CD} 25^{-} \mathrm{T}$-effector cells (Teff), with or without $1 \times$ $10^{5} \mathrm{CD} 4{ }^{+} \mathrm{CD} 45 \mathrm{RB}^{10} \mathrm{CD} 25^{+} \mathrm{T}$-regulatory cells (Treg). (D) Changes in body weight; data from 1 of 3 independent experiments with similar results are expressed as mean \pm SEM ( $n=$ 8). (E) Colons were measured and weighed at 10 weeks post-transfer; data are expressed as mean $\pm \operatorname{SEM}(n=10)$. (D, E) An asterisk indicates that the mean is significantly different from the mean for control $\operatorname{Rag}^{-/-}$mice ( $\left.\mathrm{p}<0.05\right)$. (F) Colon histology from representative mice at 10 weeks post-transfer. Images of formalin-fixed colon tissues stained with hematoxylin and eosin were captured with a 20X objective. 
A

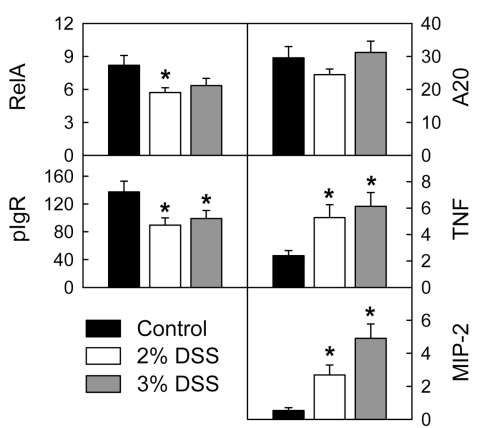

B

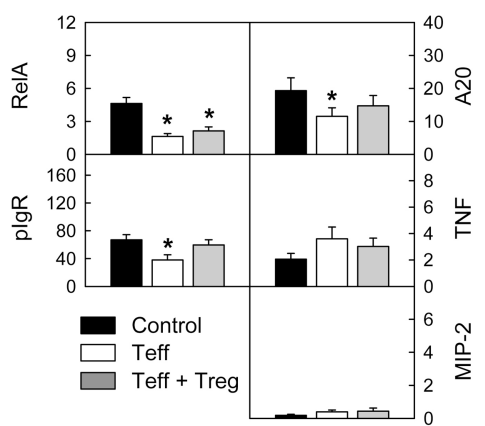

FIGURE 2.

Comparison of biomarker expression in colonic ECs in experimental colitis: (A) DSS colitis; (B) T cell transfer colitis. Colitis was induced as described in Figure 1, and colonic ECs were isolated at the end of the experiments. mRNA levels were measured by qRT-PCR and normalized to $\beta 2$-microglobulin mRNA. For each model, data from 3 independent experiments were combined and expressed as mean \pm SEM $(n=16$ for DSS colitis and $n=$ 10 for $\mathrm{T}$ cell transfer colitis). Asterisks indicate that the mean for treated mice is different from the mean for control mice $(\mathrm{p}<0.05)$. 


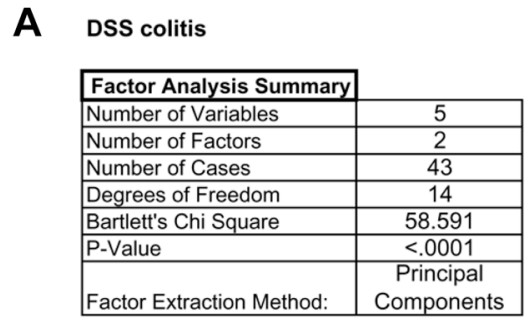

\begin{tabular}{|r|r|r|}
\hline Eigenvalues & Magnitude & $\begin{array}{c}\text { Variance } \\
\text { Proportion }\end{array}$ \\
\hline PC1 & 2.17 & 0.433 \\
\hline PC2 & 1.44 & 0.288 \\
\hline
\end{tabular}

\begin{tabular}{|l|c|r|}
\cline { 2 - 3 } \multicolumn{1}{c|}{} & \multicolumn{2}{c|}{ Coefficients } \\
\hline Variables & PC1 & \multicolumn{1}{c|}{ PC2 } \\
\hline RelA & 0.907 & 0.020 \\
\hline A20 & 0.813 & 0.337 \\
\hline plgR & 0.750 & -0.166 \\
\hline TNF & 0.099 & 0.857 \\
\hline MIP-2 & -0.335 & 0.752 \\
\hline
\end{tabular}

T cell transfer colitis

\begin{tabular}{|l|c|}
\hline Factor Analysis Summary & \multicolumn{1}{|c}{} \\
\hline Number of Variables & 5 \\
\hline Number of Factors & 2 \\
\hline Number of Cases & 30 \\
\hline Degrees of Freedom & 14 \\
\hline Bartlett's Chi Square & 62.697 \\
\hline P-Value & $<.0001$ \\
\hline Factor Extraction Method: & $\begin{array}{c}\text { Principal } \\
\text { Components }\end{array}$ \\
\hline
\end{tabular}

\begin{tabular}{|r|r|r|}
\hline Eigenvalues & Magnitude & $\begin{array}{c}\text { Variance } \\
\text { Proportion }\end{array}$ \\
\hline PC1 & 2.61 & 0.522 \\
\hline PC2 & 1.14 & 0.229 \\
\hline
\end{tabular}

\begin{tabular}{|l|c|c|}
\cline { 2 - 3 } \multicolumn{1}{c|}{} & \multicolumn{2}{c|}{ Coefficients } \\
\hline Variables & PC1 & PC2 \\
\hline RelA & 0.841 & -0.239 \\
\hline A20 & 0.919 & 0.047 \\
\hline plgR & 0.745 & 0.008 \\
\hline TNF & 0.667 & 0.554 \\
\hline MIP-2 & -0.246 & 0.882 \\
\hline
\end{tabular}

B
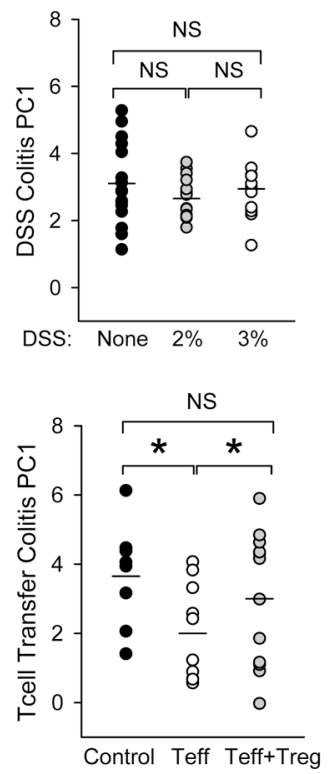
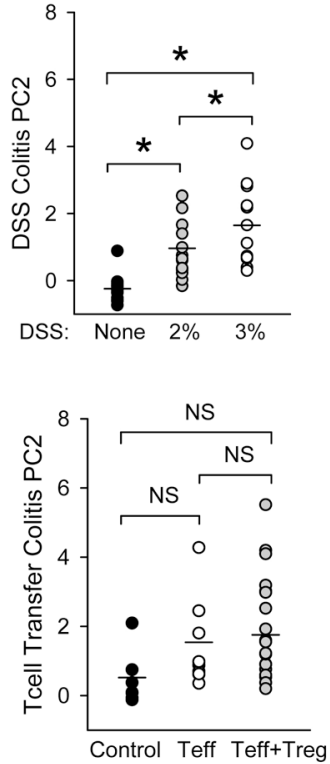

FIGURE 3.

Multifactorial analysis of biomarker expression patterns in experimental colitis, using data described in Figure 2 for mRNA levels in colonic ECs. (A) Factor analysis was used to reduce data for 5 variables, RelA, A20, pIgR, TNF and MIP-2, into two principal components (PCs). Eigenvalues indicate the proportion of variance among mice in expression of these 5 variables that can be described by PC1 and PC2. Weighted coefficients are listed for each variable comprising PC1 and PC2. (B) PC1 and PC2 scores were calculated for each individual mouse based on the sum of normalized expression levels for each variable multiplied by its corresponding coefficient for PC1 and PC2 (see Materials and Methods). Combined data from 3 independent experiments for each mouse model are expressed as mean \pm SEM ( $n \leq 14$ mice/group for DSS colitis and $n=10$ mice/group for $T$ cell transfer colitis). Asterisks indicate that the mean PC values for the indicated comparisons are significantly different $(\mathrm{p}<0.05)$; NS $=$ not significant. 


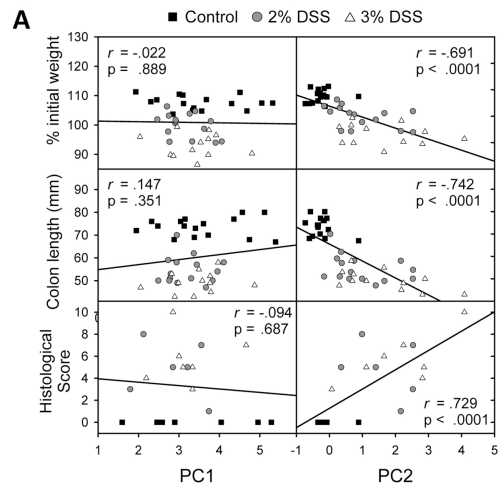

B

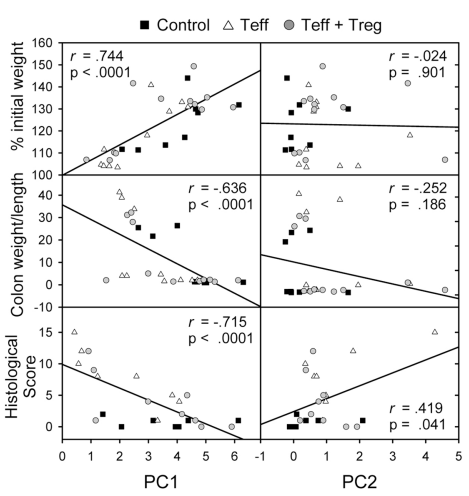

FIGURE 4.

Expression of colonic epithelial biomarkers predicts disease severity in experimental colitis: (A) DSS colitis; (B) T cell transfer colitis. Plots depict linear regression comparing PC1 and PC2 scores for each mouse to body weight at the end of the experiment, colon length (DSS colitis) or the ratio of colon weight to length ( $\mathrm{T}$ cell transfer colitis), and histological colitis scores. Correlation coefficients ( $r$ ) and P-values ( $\mathrm{p}$ ) are listed for each regression line. 

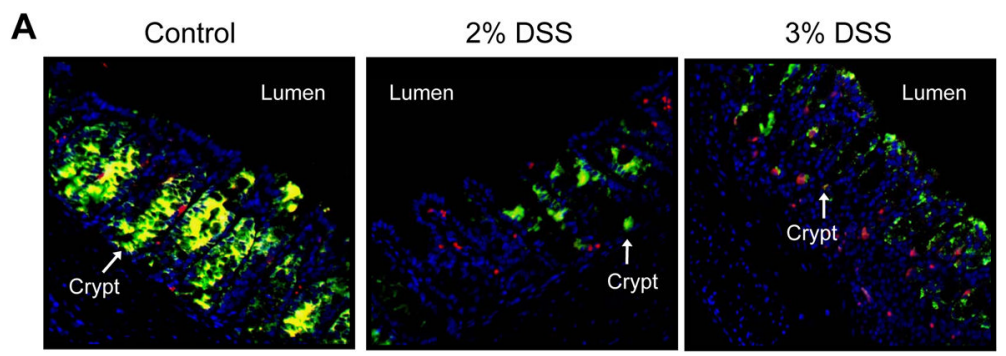

B
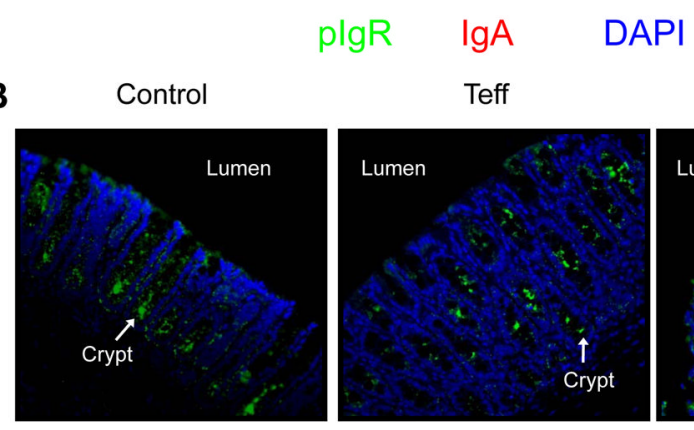

Teff

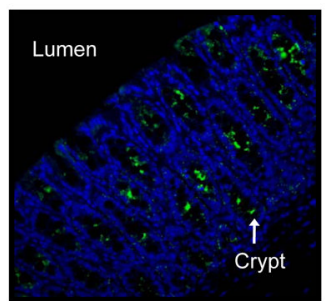

Teff + Treg

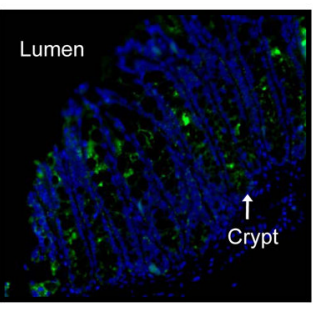

FIGURE 5.

Localization of pIgR and IgA in colonic mucosa of mice with experimental colitis: (A) DSS colitis; (B) T cell transfer colitis. Sections of formalin-fixed colons were stained by immunofluorescence for $\mathrm{pIgR}$ (green), IgA (red) and nuclei (DAPI; blue). Representative images are shown for each treatment group. Images were captured with a $25 \mathrm{X}$ objective. 